\title{
PRACTICAL HINTS
}

\section{a)}

The Preparation of Rubber Gloves for Subgical Use.-This can best be accomplished where there are the conveniences of hot- and cold-water faucets. As the soiled gloves are returned after operations it is a good plan to place them immediately in a pail of tepid water, to which a little washing-soda has been added. This softens up, and prevents the blood from drying on the rubber.

The gloves are then taken out separately and laid on a slab, and scrubbed with a fairly stiff brush and a weak soda solution: should there be any difficulty in removing some of the stains a little ordinary borax soap may be used, though, as a rule, the soap tends to leave the rubber sticky.

In scrubbing the gloves care must be taken that they are thoroughly cleaned, especially about and between the fingers, and, of course, they must be cleaned on both sides. In order to turn them, first pass the fingers downward through the opening, as though to invert the glove, and then fll up the pocket, or palm, with water, when it will be found that the force of the weight will make the fingers fall readily into place again-only the glove has been turned.

Now they must be well rinsed, and the best and easiest way to do this is to hold them under a running hot-water tap, and as each one is finished lay it with the fingers higher than the opening, so that most of the water may drain off.

It is important that the gloves be well dried after cleaning, and for this purpose use a good, firm, dry pad to work upon (a folded sheet answers well), and use soft absorbent towelling for the drying.

When one side is thoroughly dry commence to turn the gloves as before by passing the fingers through the opening; shake them down as far as possible, then fold or close the opening, and by holding it so, at either end of the aperture, firmly stretched, throw the glove once or twice over itself, when the palm will become flled with air, then by squeezing this on towards the fingers, they will be forced out again to their natural shape. If this cannot be readily accomplished, it is either because the glove was not held firmly enough and the air was allowed to escape, or because there is a puncture somewhere.

After thoroughly drying on both sides the gloves may be prepared for surgical use.

Some surgeons prefer having them powdered inside, for in this way they are much more easily put on. Talc, or soapstone powder, is perhaps the most satisfactory, and in order to apply it, sprinkle freely on the glove and distribute it evenly with the hand or a piece of gauze, then turn your glove once more, so that the powder may be on the inside.

Gloves are sterilized by boiling usually, and to keep the inside dry, take each pair, place the folded openings together tightly, in several folds, and secure them by a firm tourniquet of small rubber tubing: this, if properly adjusted, will prevent any water from getting inside.

Four pairs of gloves are generally required for each operation, and they may be placed in a bag made with a pocket numbered for each pair, or they may be rolled in a towel and boiled for ten minutes.

(Method of the Massachusetts General Hospital Amphitheatre.) 
Simple Method of Artificial Respiration.-Dr. J. V. Laborde, of Paris, has published the following simple method for the restoration of drowning persons. The translation is from a leaffet which he distributes among his pupils, and in one case cited, a child that had been submerged fifteen minutes, breathing was restored in ten minutes:

“ 1 . As soon as the drowning man has been taken from the water, force open his mouth. If the teeth are clenched, separate them with the fingers or by means of any hard object-a piece of wood, the end of a cane, the handle of a knife, of a spoon, of a fork.

" 2. Firmly seize between the thumb and the first finger of the right hand the end of the tongue, using your handkerchief or any piece of linen to prevent the tongue from slipping; then repeatedly, rhythmically, and with decision pull it from the mouth and relax it alternately-at the rate of at least twenty times a minute, imitating the cadenced movements of expiration and inspiration.

“3. At the same time introduce far back into the throat the first finger of the left hand, pressing upon the base of the tongue, so as to induce vomiting, and thus free the stomach of the water or food which encumbers it.

" 4. This treatment, the most efficacious known method of bringing back the respiration, must be begun without the slightest delay, and persistently continued for a half-hour, an hour, or more. At the same time all the usual remedies must be applied. Most inportant are the removal of the clothing, friction over the whole body, pressure upon the anterior part of the chest, the restoration of the bodily heat, and, where it is possible, the application upon the region of the heart of compresses of very hot water.

"The same method may and should be applied, in the same manner, in all cases of asphyxia and of syncope (loss of consciousness), from whatever cause."

Typhold Fever from Sources othen than Water Supply.-Burying typhoid material in the earth without adequate disinfection is the surcst way of perpetuating the disease and causing it to become endemic. The bacillus grows to the surface like a fungus in a hot-bed and there is cvidence that it thrives luxuriantly amidst processes which originate nitrites and nitrates in soil and water. The water may be contaminated from these deposits, infection may bc carried from them by flies or the wind, or garden produce may be polluted. The closet arrangements at many picnic grounds are responsible for cases. There may be a spore stage in which the disease is air-borne. Instant disinfection of dejecta with copper sulphate would almost make the disease extinct inside of a year.-H. M. 